\title{
LAHKO BOJNO LETALSTVO V PROTIUPORNIŠKEM DELOVANJU IN ANALIZA UPORABE PILATUSA PC-9
}

\section{MILITARY AVIATION IN COUNTER-INSURGENCY OPERATIONS AND ANALYSIS OF THE USE OF PILATUS PC-9}

Povzetek Besedilo proučuje uporabo lahkega bojnega letalstva v protiuporniških operacijah $v$ nekaterih oboroženih spopadih od druge svetovne vojne do danes. Primerja načine uporabe lahkega bojnega letalstva in sodobna lahka bojna letala v različnih protiuporniških vojnah v tem obdobju. Ugotavlja možnosti uporabe letala Pilatus PC-9, ki se uporablja tudi v Slovenski vojski, v prihodnjih protiuporniških operacijah zavezništva Nato.

Ključne Protiuporništvo, lahko bojno letalstvo, letalska podpora, letalo Pilatus PC-9. besede

Abstract The article discusses the use of military aviation in counter-insurgency operations in some armed conflicts since World War II up to this day. It compares the principles of the use of counter-insurgency aviation and different types of fixed-wing light attack aircraft in this period of time. It provides an analysis of the possibility of using Slovenian Armed Forces Pilatus PC-9 in future NATO COIN operations.

Key words Military aviation, counter insurgency, air support, Pilatus PC-9.

Uvod Natove letalske sile zveze in njihova doktrina uporabe izhajajo še iz časa medblokovske napetosti, hladne vojne in grožnje jedrskega ali totalnega klasičnega vojaškega spopada. V letih po razpadu Varšavskega pakta in Sovjetske zveze so se grožnje, na katere bi bilo treba odgovoriti s silo, tudi z letalskimi silami, spremenile. Države in njihova vojaška letalstva so se novim razmeram delno prilagodili, predvsem z razvojem streliva in oborožitvenih sistemov, ki so jih letala nosila, letala pa se v svojem konceptu niso toliko spreminjala. Tako smo na začetku invazije na Afganistan lahko videli delovanje strateškega bombniškega letalstva ZDA, letal, 
ki so v temeljih namenjena jedrskemu udaru, proti popolnoma asimetrični grožnji, pretežno pehotni talibanski vojski in pozneje njenim ostankom. Tako uporabo velikih in dragih bombnikov je omogočalo sofisticirano strelivo, odvrženo z velikih višin, kot so laserske in GPS-vodene bombe, ki so ga usmerjali specialisti na tleh, pripadniki ameriškega vojnega letalstva in pripadniki specialnih sil ZDA ter Združenega kraljestva. Uporaba vseh teh elementov je bila zelo uspešna, v trenutku invazije najprimernejša, vendar tudi zelo draga. S preobrazbo invazije na Afganistan v okupacijo in posledično dolgotrajno protiuporniško vojno proti različnim oboroženim skupinam v Afganistanu, ki redko po svoji velikosti ali pomembnosti zahtevajo ali vsaj upravičijo angažiranje tako dragih in visokotehnoloških oborožitvenih sistemov, pa so se pojavile zahteve za zagotavljanje cenejše podpore iz zraka.

Zračna podpora te vrste ni popolna novost v vojskovanju. Iz veliko protiuporniških vojn in operacij v drugi polovici 20. stoletja in v prvih letih novega so znane dobre izkušnje protiuporniškega delovanja letalstva $\mathrm{z}$ veliko cenejšimi in preprostejšimi letali. Kljub tem pa niso bili učinki nič slabši.

Z izrazom protiuporniško (angl. counterinsurgency - COIN) delovanje se označuje vojaško delovanje zakonite vlade tehnološko in razvojno superiorne strani, ki ji pri stabilizaciji varnostnih razmer pomaga mednarodna vojaška organizacija (v njeni sestavi je lahko tudi Slovenska vojska), ki ima za protiuporniško delovanje mandat Varnostnega sveta Združenih narodov in nastopa proti tehnološko, kadrovsko in organizacijsko inferiornemu nasprotniku, ki nima svojega letalstva in za posredovanje na bojišču ali v zračnem prostoru lahko redko uporabi le zastarela ter improvizirana bojna sredstva ter sredstva zračne obrambe. Pri tem so uporniki posamezniki, organizirane in neorganizirane skupine, ki nasprotujejo mednarodno priznani vladi ali organizaciji ter želijo, večinoma prikrito, z metodami partizanskega in gverilskega delovanja spremeniti politično-varnostno stanje v neki regiji, da bi dosegli ideološki, politični ali ekonomski cilj.

\section{LAHKO BOJNO LETALSTVO}

Spekter mogočih vojaških spopadov se je v zadnjih desetletjih precej razširil in zelo težko je izdelati letalo, ki bi bilo uporabno v vseh okoliščinah. Pri tem je zelo pomembno razmerje med ceno in učinkovitostjo. Postalo je jasno, da najsodobnejša hitra letala ne morejo popolnoma izkoristiti svojih zmožnosti. Realnost lokalnih spopadov je splošno znana in $\mathrm{z}$ njo narašča potreba po letalstvu z optimalnimi lastnostmi za te vrste spopadov. Izoblikovala se je tudi misel, da ni mogoče izdelati letala $\mathrm{z}$ zelo širokim spektrom delovanja za vse vrste vojaških konfliktov. Vse večje zanimanje za lahko bojno letalstvo ni le posledica ekonomskih razlogov ali izum držav z omejenimi vojaškimi proračuni. Prav ZDA spodbujajo njegov razvoj. Američani so že v Koreji opazili, da je manjše točkaste cilje lažje napasti z letalom za prehodno šolanje Howard kot s takrat najsodobnejšim lovskim bombnikom F-86G. Seveda to velja le tedaj, ko cilji niso resneje protizračno branjeni (Rendulić, 1974, str. 380). 
Pod pojmom lahko bojno letalstvo (LBL) v tem članku se razumejo lahki oboroženi in neoboroženi zrakoplovi (letala in helikopterji), namenjeni predvsem za omejeno ognjeno podporo enotam na zemlji oziroma samostojno ognjeno delovanje po objektih, enotah in sredstvih upornikov; izvidovanje, opazovanje in kontrolo bojišča ter transport ljudi in sredstev, namenjenih protiuporništvu. V ta razred spadajo vsa slovenska letala in helikopterji, tudi Pilatus PC-9M.

Lahko bojno letalo je zrakoplov z majhno hitrostjo letenja (do $1000 \mathrm{~km} / \mathrm{h}$ ), z majhno nosilnostjo (do $2500 \mathrm{~kg}$ ), relativno kratko vzletno in pristajalno razdaljo ter načeloma z možnostjo vzletanja in pristajanja na travnatih površinah (Ratković, 1981, str. 250).

Lahko bojno letalstvo je del bojnega letalstva, namenjenega ognjenemu delovanju po slabše branjenih ciljih na pomožnih smereh delovanja ter na hribovitem in goratem zemljišču: lahko izvaja izvidniške naloge ali deluje proti helikopterjem in letalom z manjšimi hitrostmi letenja. Naloge izvaja načeloma ponoči, v majhnih skupinah ali posamezno $\mathrm{v}$ zahtevnem vremenu, podnevi pa $\mathrm{v}$ slabši protizračni obrambi nasprotnika. Organizira se v oddelke in eskadrilje, je enorodne sestave in ima enoto za vzdrževanje na I. in II. stopnji. Za naloge letalske podpore je neposredno podrejeno operativno-strateški formaciji kopenske vojske in je pogosto $\mathrm{v}$ sestavi njenega letalstva (prav tam.)

Glavne značilnosti lahkih bojnih letal so: majhna dimenzija, lahko uporabljajo travnate vzletno-pristajalne steze, so preprosta za vzdrževanje v poljskih razmerah, mogoča sta razpršeno baziranje in maskiranje, nekatera uporabljajo visokooktanski avtomobilski bencin (Radulovič, 1985, str. 38).

Učinkovito lahko izkoriščajo tudi nekatere, za preostalo letalstvo omejujoče, dejavnike, kot sta teren in vreme. Uspešno lahko delujejo v okolju, v katerem se protiuporniške sile ne srečujejo z veliko protiletalsko grožnjo. Protiuporniške sile dosegajo nad bojiščem oziroma območjem delovanja običajno zračno nadvlado (air supremacy) ali vsaj zračno premoč (air superiority).

Lahka bojna letala delujejo po manjših ciljih, ciljih slabše odpornosti in zaščite, na manjši globini in v razmerah, primernih za svoje taktično-tehnične lastnosti. Ognjeno delujejo predvsem kot ognjena podpora enotam na tleh in so omejeni $\mathrm{z}$ globino delovanja, vrsto ciljev, učinkom na cilje in močjo sil.

Naloge LBL v letalski podpori kopenski vojski so predvsem (Pravilo lovačkobombarderske avijacije, 1978):

- uničevanje manjših, neutrjenih in slabo branjenih ciljev na komunikacijah (kolon, posamičnih vozil itn.), posebno v hribih ali gorah v zahtevnem vremenu pod mejo oblakov,

- vznemirjanje sovražnika v manjši globini,

- patruljiranje v taktični in bližnji operativni globini,

- opazovanje. 
Letala lahko delujejo tudi samo kot sredstvo zastraševanja (angl. show of force). Včasih je dovolj nekaj preletov in odmetavanje vab za toplotno vodene protiletalske rakete, da uporniki prekinejo napad na koalicijske sile in se umaknejo.

Letala lahko delujejo v manjših skupinah ali paru. Dodeljeno jim je določeno območje, na katerem deluje enota na tleh in je pripravljena na klic bojno delovati po ciljih, ki jih določi (označi ali opiše) enota na tleh.

Če imajo vojaki na tleh, ki so oddaljeni nekaj deset metrov ali še manj, težave v razlikovanju upornikov od neupornikov, je nemogoče pričakovati, da jih bo lahko razlikoval pilot letala, ki leti nekaj $100 \mathrm{~km}$ na uro ter sto in več metrov nad tlemi. Da bi lahko uporabili letala $\mathrm{v}$ protiuporniških operacijah kot podporo pehoti na tleh, se odgovornost za odpiranje ognja prenese na enoto na tleh. Vojaki na tleh morajo prepoznati in določati cilje za letalstvo, pri tem pa poznati tudi zmogljivost letal in streliva, ki ga ta nosijo. Letalo, ki kroži v pripravljenosti na neki višini in oddaljenosti od območja delovanja enote na tleh, usmerjajo usmerjevalci letalske podpore. Običajno so to častniki, piloti vojnega letalstva, ki poznajo zmogljivosti letal ter njihove oborožitve in ki več ne letijo, so pa dodani kopenskim silam in se med načrtovanjem operacij in delovanjem sporazumevajo z letalstvom. Lahko pa so tudi posebej za to usposobljeni pripadniki pehotnih ali specialnih sil, ki poleg svojih nalog še usmerjajo letala. V Natu (AAP, STANAG 3680, 2008) jih imenujejo forward air controler (FAC).

V ameriških oboroženih silah, v katerih imajo letalske komponente tudi druge zvrsti oboroženih sil, kot so mornarica (Navy) in znotraj nje še marinci (Marines), prav tako pa kopenska vojska (Army) za združeno (joint) delovanje, pri katerem sodeluje več zvrsti oboroženih sil, usposablja t. i. usmerjevalce končnega napada (angl. JointTerminal Attack Controller - J-TAC). Tako so poenotili način komuniciranja med silami na tleh in letalstvom, ne glede na to, kateri zvrsti oboroženih sil pripada letalo, ki podpira enoto na tleh. V praksi pa se je pokazalo, da lahko pilotu dovolj podatkov za napad posreduje tudi pripadnik enote, ki nujno potrebuje bližnjo letalsko podporo in ni posebej izurjen za usmerjanje letal, če le dovolj natančno opiše situacijo na tleh oziroma odgovarja na vprašanja pilota po radijski zvezi. Res pa je, da taka priprava za napad traja dlje in prelaga več odgovornosti na pilota.

\section{PROTIUPORNIŠTVO}

Protiuporništvo (counterinsurgency - COIN) je vojaški izraz za oboroženi konflikt med uporniki in silami, vdanimi uradni oblasti na ozemlju, na katerem poteka konflikt. Uporniki želijo uničiti ali izbrisati politično avtoriteto oblasti med prebivalstvom, ki ga želijo nadzorovati, protiuporniške sile pa želijo zaščititi oblast in zmanjšati ali odstraniti vpliv upornikov.

Delovanje proti uporniškim silam je vrsta stabilizacijskega delovanja. Obsega aktivnosti, usmerjene proti silam, ki poskušajo s svojim nasilnim delovanjem izsiliti 
politične spremembe. S subverzivno dejavnostjo, propagando in vojaškim pritiskom poskušajo uporniške sile prepričati ali prisiliti množice, da podprejo ali sprejmejo take spremembe. Namen sodelovanja Slovenske vojske v aktivnostih proti uporniškim silam ni popolno uničenje upornikov, temveč zagotavljanje varnosti prebivalstva, zmanjševanje podpore upornikom in onemogočanje možnosti za njihovo delovanje (Furlan, 2006, str. 75).

Protiuporniško delovanje je zelo zapletena oblika bojevanja. V bistvu je to boj za podporo prebivalstva. Zaščita, blagostanje in podpora ljudem so bistveni za uspeh. Pridobivanje in vzdrževanje podpore sta velikanska izziva. Doseganje teh ciljev zahteva uskladitev prizadevanj mnogih nevojaških agencij in agencij države gostiteljice z vsestranskim pristopom (FM 3-24, 2006).

Protiuporniške operacije so običajne med okupacijo ali v oboroženem uporu proti oblasti. Protiuporništvo je lahko oboroženo razbijanje upora, skupaj s taktiko »razdeli in vladaj «, da se prekine povezava med uporništvom in prebivalstvom, v katerem poteka uporništvo. Ker je zelo težko ali nemogoče razlikovati med upornikom, podpornikom uporništva in neupornikom, je protiuporniško delovanje zapleteno in velikokrat neuspešno. Pomote pri razlikovanju uporniških borcev od neborcev lahko spremenijo mnenje populacije in okrepijo vezi med uporniki in populacijo. Samo oborožene akcije proti upornikom običajno niso dovolj. Treba je izvajati ukrepe, ki razmejijo borce od neborcev. To se običajno doseže z drugimi ukrepi - političnimi, ekonomskimi, razvojnimi, izobraževalnimi itn. Šele ko uporniki niso povezani in so pomešani s prebivalstvom, se lahko proti njim izvajajo klasične vojaške operacije. $\mathrm{V}$ teh operacijah je lahko LBL pomemben dejavnik.

Dr. David J. Kilcullen (2006), glavni strateg Urada koordinatorja za protiterorizem Ministrstva za zunanje zadeve ZDA, piše, da je protiuporništvo tekma med protiuporniškimi silami in uporniki za pravico in sposobnost, da osvojimo srce in duh prebivalstva ter jih tako pridobimo za »svojo« stvar (Kilcullen, str. 2006 a).

Kilcullen (2006) pravi, da sta cilja protiuporniškega delovanja nadzor in kontrola, to »streho nadzora« pa podpirajo trije stebri: varnostni, ekonomski in politični. Vsi trije so enako pomembni, saj če niso enakomerno razviti ali postavljeni, postane »streha« nestabilna. Preveč ekonomske pomoči s premalo varnosti ustvari oziroma postavlja več mehkih tarč ali ciljev za upornike. Na drugi strani pa previsok varnostni steber brez političnega konsenza oziroma vladanja ustvari močnejše oborožene skupine - na primer »warlordi« (sln. »gospodarji vojne«) v posovjetskem Afganistanu. V razvoju vsakega stebra merimo napredek z ocenjevanjem učinkov in legitimnosti - stopnje, kako vladne akcije sprejema prebivalstvo. Ugotavljamo, ali prebivalstvo razume delovanje vlade kot delovanje v njihovem interesu.

Končni cilj po Kilcullenovem modelu (2006) ni zmanjšanje nasilja na nič ali uboj vseh upornikov, temveč vrnitev celotnega sistema v normalno stanje. Seveda je normalno stanje v neki družbi lahko videti drugače kot pri nas. Vedno pa ne gre samo 
za doseganje nadzora, temveč tudi njegovo utrjevanje in prenos na trajne, učinkovite ter legitimne ustanove.

\section{LAHKO BOJNO LETALSTVO V PROTIUPORNIŠTVU}

Protiuporniške operacije so po naravi združene operacije - zračne in kopenske sile so medsebojno odvisni sestavni deli takih operacij. Kot je razloženo v Dodatku E (FM-3-24, 2006), dajejo zračne sile pomembno dodatno moč ameriškim in večnacionalnim silam ter silam države gostiteljice, ki se bojujejo proti upornikom. Zračne sile lahko podpirajo kopenske sile, ki izvajajo protiuporniške operacije. Zračna plovila lahko na primer napadejo upornike tudi na terenu, neprehodnem za vozila, visoko v gorah ali džungli, kar je zelo pomembno za pehoto, ki lahko takrat deluje le peš in je omejena glede opreme in oborožitve, ki jo lahko prenaša. Glede na naravo okolja, v katerem poteka protiuporniško delovanje, zračne sile največkrat prevažajo enote, opremo in zaloge ter izvajajo naloge obveščevalne dejavnosti, nadzora in izvidovanja. Zahteven teren in slabo transportno omrežje lahko zelo ovirata protiuporniške sile in dajeta prednost upornikom, zračne sile pa protiuporniškim silam pomagajo te ovire premagati. Tako te služijo kot pomembna dodatna moč in obenem omogočajo protiuporniškim silam učinkovitejše delovanje.

Zračne sile zagotavljajo protiuporniškim silam pomembno asimetrično prednost. Če uporniki zberejo konvencionalne sile, se zračne sile lahko hitro odzovejo z natančno usmerjenim ognjem. V nenadni krizi lahko zračne sile s svojo premičnostjo nemudoma premaknejo kopenske sile na kraj, kjer jih potrebujejo. Zračne sile protiuporniškim silam omogočajo delovanje na zahtevnih in oddaljenih območjih, ki jih uporniki običajno uporabljajo za varna pribežališča (FM 3-24, 2006, Dodatek E).

Današnja nizkotehnološka sredstva zračnih sil so se prav tako izkazala za učinkovita v protiuporništvu. Lahka, počasna in poceni zračna plovila so že večkrat uspešno patruljirala na mejnih območjih. Združene države in mnoge manjše države so uspešno uporabile oborožena zračna plovila kot orožje za neposredno zračno podporo v protiuporniških operacijah. Oboroženo zračno plovilo je transportni zrakoplov, prilagojen za prevažanje in izstreljevanje težkega strelnega orožja in lahke artilerije. Glavna omejitev oboroženega zračnega plovila je ranljivost na protiletalsko orožje in izstrelke. Za njegovo delovanje je nujno razmeroma varno okolje (FM 3-24, 2006, Dodatek E).

Sestavni del Killcullenovega (2006) »varnostnega« stebra je seveda tudi vojska in znotraj nje letalske sile. V hribih s slabimi cestnimi povezavami ali celo brez njih, kot je v Afganistanu ali zadnje čase znotraj GOWT (globalna vojna proti terorizmu) v vse pogosteje omenjani Afriki, je letalstvo edino sredstvo, s katerim nad sovražnika lahko prinesemo močnejše orožje. Lahko gre za helikopterske premike lahke artilerije ali za direktno podporo iz zraka - helikoptersko in podporo letal s fiksnimi krili, kar je veliko pogosteje. Za oboje velja spodnji odstavek, vendar v ospredju bodo letala s fiksnimi krili. 
Da bi lahko letalo uspešno izvajalo protiuporniške naloge, mora izpolnjevati zahteve: majhna hitrost letenja, vzdržljivost - daljši čas med vzdrževanji, preprostost vzdrževanja in kratka vzletna ter pristajalna razdalja na grobih vzletno-pristajalnih stezah. Našteta merila večinoma izpolnjujejo le letala lahkega bojnega letalstva, ki so $\mathrm{v}$ bistvu nizkotehnološka bojna sredstva, čeprav so pogosto opremljena $\mathrm{z}$ visokotehnološkim orožjem, senzorji in komunikacijskimi napravami.

\subsection{Zgodovinski primeri uporabe lahkega bojnega letalstva v protiuporništvu}

Zgodovina opaža v zadnjih 70 in več letih uporabo letalstva v veliko protiuporniških vojnah in konfliktih z uporniki. Dogajala se je na vseh celinah in različnih terenih ter v podnebju - od priobalnega območja do visokih gora, od puščave do džungle, na Arktiki in v tropih. V nadaljevanju bodo omenjene nekatere najpomembnejše izkušnje iz teh spopadov.

\subsubsection{Boj proti partizanom v drugi svetovni vojni}

Lahka bojna letala je v protiuporniških operacijah v drugi svetovni vojni intenzivno uporabljala že nemška vojska $\mathrm{v}$ bojih proti partizanom, na primer v Jugoslaviji in Sovjetski zvezi. Uporabljala jih je predvsem za iskanje partizanskih enot iz zraka in neposredne napade na koncentrirane partizanske sile. Letala, ki jih je okupator uporabljal proti partizanskim enotam, so bila opremljena z 2-4 mitraljezi kalibra $7,9 \mathrm{~mm}$ in so lahko nosila od 400 do $1000 \mathrm{~kg}$ bomb. Samo na območju Jugoslavije je agresor od začetka vojne pa do sredine leta 1944 v boju s partizani uporabljal 360-400 letal. Med njimi so bili seveda tudi starejši zrakoplovi, ki pa so bili zelo uporabni proti nasprotniku, ki ni imel protiletalske obrambe (Radulovič, 1985, str. 43).

Radulović (1985, str. 44-46) analizira uporabo letalstva v Operaciji Schwartz (bitka na Sutjeski), ki je potekala v planinah, brez cest in komunikacij, v glavnem na pogozdenem in delno pogozdenem zemljišču s kanaliziranimi smermi. Enote narodnoosvobodilne vojske niso imele orožja protiletalske obrambe, zato je imelo sovražnikovo letalstvo možnost, da popolnoma izkoristi svoje sposobnosti. Za splošni uspeh operacije je bilo najpomembnejše vsakodnevno izvidovanje iz zraka. Bojno delovanje letalstva $v$ tej operaciji je predvsem imelo vse značilnosti bližnje letalske podpore. Glavni cilji so bili partizanske enote med premikom v kolonah, prehodi čez reke in druge zožitve. Približno 160-180 letal je v tem času opravilo med 2000 in 2500 bojnih poletov (angl. sorties, srh. aviopoletanje) (prav tam, str. 44-46).

\subsubsection{Francoska vojska v Alžiriji}

Tudi francoska vojska je v Alžiriji za napade na upornike uporabljala letala iz druge svetovne vojne z batnimi motorji, razvila pa je tudi letala za protigverilsko bojevanje Potez-75, Voltiger in Spirale. Ta so bila precej uspešna, zlasti ko Alžirci še niso imeli protiletalskih mitraljezov (Rendulić, 1974, str. 382). 


\subsubsection{Američani v Vietnamu}

Naslednja večja vojna, v kateri so uspešno uporabljali ta letala, je vietnamska vojna, najprej Francija-Vietminh in pozneje ZDA-Vietcong. V prvih letih vojne se je intenzivno uporabljal tudi Thunderbolt A-1 »Skyraider«, propelersko letalo z batnim motorjem, z malo hitrostjo letenja in veliko nosilnostjo. To mornariško palubno letalo je letelo tudi že v korejski vojni.

Med ameriškim posredovanjem v Vietnamu je bilo posebej za protiuporništvo zasnovano letalo OV-10 Bronco podjetja North American. Namenjeno je bilo večinoma vojaški uporabi, ki je vključevala protigverilske operacije, spremstvo helikopterjev, bližnjo letalsko podporo, oboroženo izvidništvo in usmerjanje topniškega ognja. Dodatno je lahko izvajalo večnamenske naloge, kot so odmetavanje tovora s padali, prevoz do šestih padalcev ali prevoz dveh pacientov na nosilih $\mathrm{s}$ spremljevalcem ter psihološko vojskovanje $\mathrm{z}$ odmetavanjem letakov in oddajanjem zvočnih sporočil po zvočnikih. Čeprav ni doseglo vseh razpisanih značilnosti, je ideja spodbudila domišljijo veliko letalskih tovarn, saj so bili taki projekti uporabni za mnoge afriške in južnoameriške države (Rendulić, 1974, str. 387). OV-10 še leti v letalskih silah nekaterih držav, na primer na Filipinih, kjer ga poleg iskanja in reševanja uporabljajo predvsem za njegov glavni namen - protiuporniško delovanje v boju z militantnimi muslimani na južnem otoku Mindanao (Knific, 2013). V resnici so Rodezijci uporabljali podobno letalo, kot sugerira Rendulić (1974), v svoji protiuporniški vojni.

\subsubsection{Rodezija}

Rodezijsko vojno letalstvo je po odcepitvi države od Združenega kraljestva v svoji petnajstletni (1965-1980) vojni proti uporniškim skupinam črnske večine, ki so temeljile in se urile ter v Rodezijo prihajale iz sosednjih Zambije, Mozambika in tudi Bocvane, uporabljalo več vrst civilnih letal, ki so tako dobila vojaško vlogo. V Rodeziji so potekale različne sankcije Velike Britanije pa tudi Združenih narodov, zaradi svoje enostranske odločitve o odcepitvi in vztrajanju na rasni segregaciji, med katerimi je bila tudi prepoved prodaje vojaške opreme tej državi. Tako je morala uporabiti zastarele vojaške pa tudi preurejene civilne zrakoplove in orožje zanje. Z njimi so podpirali delovanje svoje izvrstne lahke pehote in drugih enot na tleh. Tehnološki primanjkljaj so uspešno nadomestili z izurjenostjo borcev in inovativnostjo ter prilagodljivostjo $\mathrm{v}$ taktiki in pri izdelavi oborožitve (Croukamp, 2006; French, 2012).

Za iskanje uporniških skupin in njihovih taborov, prevoz padalcev, evakuacijo ranjencev in bližnjo letalsko podporo so uporabljali tudi letalo Cessna 337 Super Skymaster, t. i. »push-pull«, oboroženo s po dvema mitraljezoma Browning .303, na nadkrilnih nosilcih in lanserjih nevodenih raket ali bomb pod krili. Za uporabo na tem letalu, ki so ga Rodezijci imenovali »Lynx« (Ris), so razvili tudi mini, 80-kilogramsko verzijo svoje, doma razvite in izdelane 450-kilogramske bombe, imenovane Golf (Petter-Bowyer, 2012). 


\subsection{Lahko bojno letalstvo $v$ zasebnih vojaških podjetjih}

Lahkega bojnega letalstva ne uporabljajo le redne državne vojske, ki iščejo cenejšo alternativo reaktivnim letalom za protiuporniške naloge. Zaradi nizke cene in cenejšega vzdrževanja ter drugih prednosti izbirajo ta letala tudi vse bolj prisotna zasebna vojaška podjetja, ki jih imajo bodisi v lasti ali jih najemajo za operacije, včasih tudi skupaj s piloti. Eno najbolj znanih in uspešnih podjetij, Executive Outcomes iz Južnoafriške republike, je uspešno delovalo v devetdesetih letih prejšnjega stoletja v Afriki po naročilu vlad Angole in Sierre Leone. Uporabljali so tri letala PC-7, predvsem za izvidništvo in bližnjo letalsko podporo. O tem piše nekdanji poveljnik Roelf Van Heerden (2012).

\subsection{Lahko bojno letalstvo v protiuporništvu danes}

Hkratno vodenje dveh manjših protiuporniških vojn v Iraku in Afganistanu je pri ameriških strategih ponovno obudilo razmišljanje o protiuporniški letalski komponenti. Načrtovalci $\mathrm{v}$ poveljstvu specialnih operacij ameriškega vojnega letalstva US Air Force Special Operations Command (AFSOC) so že leta 2006 pozivali k vzpostavitvi novega polka za nekonvencionalno bojevanje, namenjenega za boj proti upornikom in teroristom, ki naj bi imel 44 transportnih letal, 20 helikopterjev in 20 turbopropelerskih bojnih letal (Trimble, 2007).

Tudi druge države, ki se doma ali onstran svojih meja bojujejo proti uporniškim skupinam z ideološkimi, političnimi ali ekonomskimi razlogi, uporabljajo ali načrtujejo uporabo take vrste letalstva. Univerzalnejši naziv, ki se uporablja v zadnjem času, je lahka letalska podpora - LAS (Light Air Support). Z letali te vrste Američani opremljajo afganistanski zračni korpus pa tudi letalske sile Iraka. Tokrat niso poskušali na novo izdelati idealnega protiuporniškega letala, temveč so razmišljali, katera že izdelana plovila bi bila najprimernejša. Že leta 2006 so objavili razpis (US Air Force, 2007) za osem letal za protiuporniško delovanje za na novo nastajajočo iraško vojsko. Želeli so platforme, prilagojene za boj proti upornikom v Iraku.

Za protiuporniško eskadriljo iraškega vojnega letalstva so se prijavili proizvajalci z letali (navedenimi v nadaljevanju), ki so hkrati tudi tipični predstavniki lahkega bojnega letalstva (Flightglobal, 2014).

\subsubsection{Embraer A29 Super Tucano}

Za protiuporniške naloge izdelan Tucano je tipično zračno plovilo lahke letalske podpore in že nekaj časa priznano v spopadih z uporniki po vsem svetu. Do leta 2012 je več kot 150 izdelanih letal v svetu naletelo skupno že 130.000 ur letenja z več kot 18.000 urami bojnih naletov in pri tem ni zaznalo izgub. 350 milijonov dolarjev vredna pogodba bo Afganistanskim zračnim silam prinesla najmanj 20 letal Super Tucano, s katerimi bodo po letu 2014 samostojno nadaljevali boj z uporniki. Nova pridobitev bo prinesla vsestranskost, izvidniške zmogljivosti in možnost dostave preciznega orožja Afganistanskim oboroženim silam (Fahey, 2012). 
Poveljnik NATO Air Training Command - Afghanistan, letalski brig. gen. Tim Ray, pravi, da je Tucano najprimernejši za protiuporniške naloge v Afganistanu.

»Prihod LAS-letal označuje mejnik in premik od transportnih helikopterskih zmogljivosti proti ofenzivnejšim nalogam. Tucano je najbolj kinetično in ofenzivno letalo, kar jih bodo Afganistanci imeli, in zagotovo tudi moralna spodbuda enotam na tleh. Je pravo letalo za ta teren, boj in najpomembnejše, preprost za vzdrževanje. /.../ Uporaba LAS predstavlja le delček stroškov drugih letal za bojno podporo. Motor letala je neverjetno zanesljiv in preprost. Enake motorje imamo v Cessni 208 in to so najbolj zanesljivi motorji v letalski industriji, kar jih poznam.« (Fahey, 2012)

\subsubsection{T-6A Texan II Beechcraft}

Gre za ameriško verzijo Pilatusa PC-9M, ki so ga najprej imenovali Beech Pilatus PC-9 Mk. II in pozneje preimenovali v Beechcraft T-6A Texan II. Izdeluje in trži ga Beechcraft Corporation, Pilatus pa dobiva licenčnino. Do zdaj so izdelali več kot 600 primerkov, predvsem za ameriško vojno letalstvo in mornarico (Beechcraft, 2014).

\subsubsection{AT-802U - Airtractor}

Letalo Airtractor poznamo že dolgo kot zračno plovilo za različne naloge, kot so škropljenje poljščin, opazovanje in gašenje požarov - za to jih ima tudi Hrvaška. Izdelanih je že več kot 2500 primerkov, ki letijo v ZDA in drugod po svetu. Zanesljivo in zmogljivo letalo, ki lahko nosi precej koristnega tovora, so prepoznali kot potencialno vojaško platformo in jo ponudili na trgu protiuporniškega letalstva. AT-802U je letalo z zelo nizko ceno ure letenja. Pri 450 urah letnega naleta naj bi ura letenja s tem letalom stala manj kot 400 ameriških dolarjev (AT-802U, 2014).

AT-802U je sposoben uporabe široke palete oborožitve - nosi lahko dva 12,7-mm tricevna mitraljeza Gatling, dva 7-cevna raketna lanserja in $450 \mathrm{~kg}$ bomb na devetih krilnih in trupnih nosilcih. AT-802U se po želji kupca lahko prilagodi tudi za naprednejše sisteme - lasersko vodeno strelivo, prikazovalniki v čeladi, sistemi nadzora ognja, sistemi za povečanje preživetja in razni senzorji (prav tam). AT-802U ščiti posadko s posebej zasnovanim oklepom za pilotsko kabino in motor, z neprebojnim (balističnim) steklom in s samozatesnitvenimi rezervoarji. AT-802 je bojno preverjen $\mathrm{v}$ operacijah proti proizvajalcem in preprodajalcem prepovedanih drog v Južni in Srednji Ameriki, kjer ga uporablja ameriško zunanje ministrstvo. Kljub več kot dvesto zadetkom iz lahke pehotne oborožitve, ki so jih tam prejela ta letala, so posadke zaznale 100-odstotno varnost letenja brez izgube življenj ali poškodb (prav tam).

S ceno približno 3 milijone ameriških dolarjev, brez senzorjev in oborožitve predstavlja AT-802U le tretjino nabavne cene jurišnega helikopterja (Waldron, 2013). 


\subsubsection{Pilatus PC-9}

Prav Pilatusov PC-9 je bil vzor za ameriško šolsko bojno letalo podjetja Beechcraft AT-6, ki se danes poleg Tucana najpogosteje pojavlja kot konkurent na razpisih za nakup letal za protiuporniško delovanje. Vrhunski švicarski izdelek je zelo uspešen predvsem kot šolsko letalo v mnogih vojaških letalstvih po svetu. Izdelali so že več kot 260 primerkov (PC-9 \& PC-9 M), ki so jih prodali 15 letalskim silam po svetu. V oborožitvi jih ima tudi Slovenska vojska (Pilatus, 2014).

Še prej so uspešno prodali njegovega starejšega brata PC-7 v 500 primerkih (PC-7 \& PC-7 MkII) 21 vojnim letalstvom (Pilatus, 2014 a).

Slovenski PC-M9 so bili z izraelskim podjetjem Radom Aviation Systems nadgrajeni v verzijo »Hudournik « in so tako edini PC-9 v Natu, ki so prilagojeni za bojne naloge, tudi bombardiranje, čeprav imajo oborožene PC-9 tudi Irci in Bolgari (mitraljezi in nevodene rakete) ter neoborožene Hrvati. Z nadgradnjo postane to turbopropelersko letalo primerljivo s češkim reaktivnim šolskim bojnim letalom L-159 ALCA (Otten, 2009).

Vsa ta letala so primerna za naloge v protiuporniškem delovanju (Beechcraft, 2014), kot so bližnja letalska podpora, usmerjanje topniškega ognja iz zraka, oboroženo izvidništvo, usklajevanje udara in izvidovanje, prestrezanje iz zraka, obveščevalna dejavnost, nadzor in izvidništvo.

\section{PC-9 V PROTIUPORNIŠTVU}

Letalo Pilatus PC-9 je razvito predvsem kot šolsko letalo za usposabljanje vojaških pilotov. Praviloma je opremljeno $\mathrm{z}$ vsemi instrumenti in sredstvi kot reaktivno letalo, vendar je letenje z njim predvsem cenejše, kar je za šolanje in tudi bojno uporabo na bojiščih, kjer ni izrazite protiletalske grožnje, racionalna izbira. Slovenska izpopolnjena različica Hudournik ima vgrajeno vso avioniko, da lahko uporablja tudi sodobno oborožitev, kot so GPS in lasersko vodene bombe J-DAM, ki omogočajo natančno zadevanje ciljev s kar največjim učinkom na cilj in minimalno kolateralno škodo. Poleg tega je lahko oborožen z mitraljezi 12,7 in nevodenimi raketami. Sposobno je vzletati in pristajati s krajših vzletno pristajalnih stez, relativno dolgega poleta in nositi dovolj velik bojni tovor. Vzdrževanje je relativno poceni in preprosto. Vzdrževanje na II. stopnji lahko po 150 urah letenja opravi skupina le štirih mehanikov.

Ura letenja turbopropelerskega letala PC-9 je ocenjena na okoli 1000 evrov, kar je bistveno manj, kot stane ura reaktivnega letala (do nekaj $10.000 €$ ) ali helikopterja (več $1000 €$ ), vzdrževanje na II. stopnji lahko opravlja ekipa štirih mehanikov in letalo je lahko z bojnim tovorom v zraku celo do štiri ure. 
Vse to uvršča PC-9 med najbolj rentabilna letala za delovanje proti ciljem na tleh, ki niso resneje protiletalsko branjeni in pri katerih $\mathrm{v}$ zraku dosegamo popolno nadvlado. Pregled taktično-tehničnih podatkov PC-9 pokaže, da ima letalo vse tiste lastnosti, ki jih lahko bojno letalstvo potrebuje za operacije v protiuporniškem delovanju.

Med službovanjem v Afganistanu sem se seznanjal z delovanjem Natovih sil na območju delovanja. Zanimalo me je predvsem delovanje kopenskih sil ob podpori letalstva, ki je zaradi geografskih značilnosti nujno. Pri tem sem tudi razmišljal o možnostih uporabe slovenskih PC-9 v protiuporniškem delovanju zveze Nato $\mathrm{v}$ operaciji Isaf. Naloge teh letal v Afganistanu vidim predvsem kot zagotavljanje bližnje letalske podpore enotam na tleh ter spremstvo transportnih helikopterjev pri prevozu moštva ali opreme. Poleg tega bi lahko izvajali patruljiranje nad celotnim območjem delovanja, zlasti ob glavnih komunikacijah, podnevi in ponoči, kot obveščanje o premikih sumljivih vozil in skupin ter tako preprečevanje napadov z improviziranimi eksplozivnimi sredstvi na oskrbovalnih poteh. Prav tako lahko ta letala zaradi majhne hitrosti letenja izvidujejo in spremljajo premike na tleh.

Letalsko podporo kopenskim enotam bi lahko zagotavljali z letališča, ki je najbližje območju operacij. Tam bi bila nameščena tudi glavna ekipa na tleh, najboljša lokacija za glavno bazo za popravila in vzdrževanje bi bila letališče v Heratu, kjer je najbolje urejena infrastruktura. Tam bi lahko bilo tudi tehnično osebje za vzdrževanje na II. stopnji. S predpisanimi pregledi na 100-150 ur letenja je PC-9M med zelo vzdržljivimi letali. Nizki stroški vzdrževanja in daljši čas letenja med pregledi so zelo pomemben logistični dejavnik na območju delovanja, kamor je treba vse nadomestne dele in opremo pripeljati z zračnim mostom ali s precej tveganimi konvoji po tleh.

S prestavljanjem letal na periferna letališča, bližja območju delovanja, za vnaprej načrtovane operacije, bi dobili krajši odzivni čas letal v pripravljenosti in daljši čas delovanja nad ciljem. Nujno število letal za delovanje bi bilo 5-7, kar pomeni, da imamo lahko vedno nekaj letal v zraku ali takojšnji pripravljenosti, nekaj $\mathrm{v}$ pripravljenosti z daljšim odzivnim časom ter letalo v rezervi ali vzdrževanju. Pri sedmih letalih imamo v rezervi cel par ali pa se na njih lahko izvajajo periodični pregledi ali vzdrževanje. Optimalno bi potrebovali dvojno število pilotov za vsako letalo in ustrezno število zemeljskega osebja za oskrbovanje in vzdrževanje (mehaniki, orožarji).

Zaradi zmožnosti uporabe standardne zahodne oborožitve bi lahko za oskrbo s strelivom in gorivom sklenili pogodbo s katero od držav zavezništva, kar je bila praksa tudi na drugih področjih (npr. vozila).

SV že več kot deset let deluje v zahodnem delu Afganistana, v regionalnem poveljstvu Zahod (Regional Command-West; RC-W), ki obsega štiri province: Badghis, Ghor, Herat in Farah. Poleg letališča v Heratu, ki ima dve betonski stezi in vso infrastrukturo - tam so bili nameščeni tudi transportni in bojni helikopterji, transportna in brezpilotna letala ter lovski bombniki Panavia Tornado - je v RC-W 
še več letališč, s katerih bi lahko delovala letala PC-9. Skoraj vsak pomembnejši kraj v regiji ima letališče. Letališča med sabo niso oddaljena več kot $150 \mathrm{~km}$ (Global Security, 2014). Nameščeni na letališčih Herat, Farah ali Shindand bi lahko z akcijskim radijem $750 \mathrm{~km}$ pokrivali delovanje afganistanskih varnostnih sil in zavezniških enot v vsej regiji s časom nad ciljem do 4 ure ter časom leta od letališča do cilja največ 30 minut.

Podatkov o uporabi PC-9 v kateri od protiuporniških operacij ni bilo zaslediti, so pa predhodnika Pilatus PC-7 uspešno uporabljali v protiuporniških operacijah v Afriki, kjer ga je podjetje Executive Outcomes uporabljalo v protiuporniških operacijah v Angoli leta 1997 in pozneje v Sierri Leone. Podjetje so najele vlade teh dveh držav, da je z letali pomagalo redni vladni vojski zatreti uporniške skupine na svojem ozemlju. PC-7 so uporabljali predvsem za zračno izvidništvo, opazovanje, patruljiranje, označevanje ciljev in bližnjo letalsko podporo (Venter, 2008, str. 415).

\subsection{Dodatne možnosti uporabe PC-9}

Še enkrat so lahko dober zgled Rodezijci, ki so razvili primerno oborožitev, tudi lažje, za »Lynx« primerne 80-kilogramske bombe Mini Golf. Za države, ki PC-9 imajo in niso pod sankcijami prepovedi nakupa oborožitve, temveč so celo članice Nata, ne bi bilo nujno posebej doma razvijati nove oborožitve, seveda pa je uporaba domačega znanja zaželena. Obstaja veliko različne oborožitve, ki na PC-9M še ni bila nameščena, kar pa ne pomeni, da se to ne da narediti. $\mathrm{S}$ tem se tudi razširi področje uporabe preprostega letala, kot je PC-9 M. Pri nas je dovolj znanja, da bi se lahko izdelale modifikacije, zaradi katerih bi bilo letalo še bolj uporabno.

Če bi letalo oborožili npr. z bombami tipa SDB GBU-39/B, bi povečali mogoče število napadov na poletu in zelo izboljšali verjetnost zadetka, tako pa tudi zmanjšali kolateralno škodo, kar je z vidika legitimnosti in sprejemljivosti protiuporniškega delovanja po Kilcullenu (2006) zelo pomembno. Prav tako se pri uporabi tega tipa bomb zmanjša izpostavljenost letala, saj lahko tako vodeno bombo odvrže več $10 \mathrm{~km}$ od cilja. Cena take bombe je približno 40.000 ameriških dolarjev (Oestergaard, 2014)

Sklep V svetu se pojavlja vse več zanimanja za uvedbo turbopropelerskih letal lahkega bojnega letalstva $\mathrm{v}$ letalske sile držav, ki delujejo $\mathrm{v}$ protiuporniških operacijah. Razlogi za to so njihove taktično-tehnične lastnosti in predvsem nižja cena letenja. Boljše razmerje med nabavno ceno in učinkom (cost-effectiveness) je zlasti primerno za države, ki imajo manj denarja, pa tudi za druge, ki v finančni krizi iščejo načine, kako se z manjšimi stroški spopadati z uporniki na domačem ali tujem bojišču.

Prav tako lahko bojno letalstvo v protiupornišvu ni novost, nastala v vojni proti terorizmu, temveč se uporablja že od druge svetovne vojne. Večinoma je razlog za uporabo enak: nižji stroški uporabe, kadar razmere na bojišču dopuščajo uporabo počasnejših, manj zaščitenih letal, ki pri manjših hitrostih in višinah bojno oziroma podporno delujejo proti ciljem, ki nimajo resne protiletalske obrambe in njegova velikost ne zahteva večjega bojnega tovora. Protiuporniške vojne ali konflikti so 
običajno dolgotrajni in se vedno bijejo proti slabo opremljenim in slabo izurjenim borcem, ki pa so zelo prilagodljivi na še tako izpopolnjeno tehnologijo in taktiko protiuporniških sil. Zato je v takih operacijah zelo pogosto neracionalno uporabljati draga visokotehnološka bojna sredstva, čeprav so na razpolago. Strošek uporabe ni niti približno sorazmeren uspehu na bojišču. Kot primer dobre prakse nizkotehnološkega protiuporniškega bojevanja lahko vzamemo rodezijsko lahko pehoto v sodelovanju z rodezijskim vojnim letalstvom, pri katerem gre za slabše opremljeno, vendar vrhunsko usposobljeno oboroženo silo v boju proti upornikom, ki so sicer odlično opremljeni, a slabo izurjeni.

Različne načine uporabe lahkega bojnega letalstva $\mathrm{v}$ protiuporništvu smo spoznali predvsem $\mathrm{z}$ analizo uporabe $\mathrm{v}$ preteklosti, zagotovo pa se z razvijanjem novega orožja pojavljajo tudi nove možnosti. Lahko bojno letalstvo je lahko v protiuporniških vojnah še vedno uporabno v vseh do zdaj omenjenih vlogah, od zračnega izvidništva in spremstva transportnih helikopterjev do direktnega delovanja po ciljih na tleh.

Lahko bojno letalstvo je zlasti primerno za zračno podporo protiuporniškemu delovanju zaradi mnogih prednosti, ki jih ima pred visokotehnološkim bojnim letalom z reaktivnim pogonom. Predvsem gre tu za nabavno ceno, stroške delovanja in vzdrževanja, možnosti uporabe na manjših in robustnih vzletno-pristajalnih površinah, manjše hitrosti letenja pri napadih na cilje na tleh in posledično boljše zadevanje z nevodenimi orožji itn. Zagotovo je uporaba takih letal racionalna odločitev za boj proti upornikom, ki nimajo resne protiletalske obrambe, kar dokazuje, da je lahko bojno letalstvo pomemben bojni del protiuporniškega delovanja.

Pomemben dejavnik v protiuporniškem delovanju je sposobnost teh letal, da delujejo tudi z zasilnih, manjših vzletno-pristajalnih stez, ki jih blizu območja operacije lahko hitro pripravi inženirska enota. Uporabi se lahko tudi del oziroma odsek avtoceste v bližini. Ker so letala nameščena blizu območja operacije, imajo kratek odzivni čas na klic po nujni zračni podpori in daljši čas pripravljenosti za delovanje $\mathrm{v}$ zraku. Pomemben je tudi psihološki dejavnik, saj piloti in vojaki pehote, ki jih ti piloti podpirajo, živijo v istih bazah, s čimer se poveča neposredna vpletenost pilotov $\mathrm{v}$ položaj. Pilot, ki poleta z letalonosilke, čuti drugačno odgovornost kot pilot, ki iz skupne baze odhaja podpirat vojake, s katerimi se pozna iz baze.

Pilatus PC-9, ki spada med lahka šolsko-bojna letala in je po svojih lastnostih zelo podoben drugim letalom $\mathrm{v}$ tem razredu, kar se vidi iz primerjave taktično-tehničnih lastnosti predstavljenih zrakoplovov, je prav tako primeren za izvajanje nalog lahkega bojnega letalstva v protiuporništvu.

Čeprav bodo imele letalske sile velikih vojsk tudi v prihodnosti v sestavi draga in tehnološko najsodobnejša reaktivna letala, bodo ta namenjena predvsem odvračanju napada na države in njihove zaveznice, zagotavljanju premoči v zraku in letalski podpori kopenskim operacijam večjih razsežnosti. 
V letalstvu za protiuporniško delovanje pa se odpira prostor, kamor bi lahko znotraj svojih obveznosti do zavezništva posegla tudi Slovenska vojska. Naša prednost je v tem, da taka letala in izšolane pilote že imamo. Obveznosti Republike Slovenije do Nata bi torej lahko izpolnili s sedanjimi zmogljivostmi Slovenske vojske, ki so na precej visoki ravni. Namesto da pešmergam pošiljamo inštruktorje pehotnih veščin, ki jih Kurdi več kot očitno obvladajo, bi lahko Nato ponudil Kurdom to, česar v boju z Islamsko državo nimajo - letalsko podporo slovenskih PC-9M, ki jih lahko usmerjajo slovenski J-TAC, pripadniki specialnih sil, ki so hkrati tudi operativni mentorji za letalsko podporo kurdski enoti, v nadaljevanju pa se lahko kurdski vojaki usposabljajo v slovenski šoli za bližnjo letalsko podporo.

\section{Literatura}

1. AAP, STANAG 3680, 2008. NATO Glossary of Terms and Definitions. http://fas.org/irp/ doddir/other/nato2008.pdf (29. 9. 2014).

2. AT-802U. A Versatile Aerial Platform for Counterinsurgency Flight Operations. http:// www.802u.com/ (23. 3. 2014).

3. Beechcraft. AT-6 Light Attack. http://www.beechcraft.com/military/light_attack.aspx (28. 7. 2014).

4. Croukamp, D., 2006. The Bush War in Rhodesia. Boulder, Colorado: Paladin Press.

5. Fahey, C., 2012. New airframe adds strike capability to Afghan air force: NATO Training Mission Afghanistan. http://www.dvidshub.net/news/printable/82249) (17. 3. 2014).

6. Flightglobal. US Air Force starts bidding for Iraqi counter-insurgency aircraft fleet. http://www.flightglobal.com/news/articles/us-air-force-planners-want-irreguar-warfarewing-215281/(17. 3. 2014).

7. FM 3-24, 2006: Counterinsurgency. Washington DC: Headquarters Department of the Army.

8. French, P., 2012. Shadows of forgotten past: To the edge with the Rhodesian SAS and Selous Scouts. Solihull: Helion \& Co.

9. Furlan, B., in drugi, 2006. Vojaška doktrina. Ljubljana: Poveljstvo za doktrino, razvoj in vojaško usposabljanje.

10. Global Security. Afghanistan Facilities. http://www.globalsecurity.org/military/facility/ afghanistan.htm (29. 9. 2014).

11. Kilcullen, D. J., 2006. Three Pillars of Counterinsurgency. http://www.au.af.mil/au/awc/ awcgate/uscoin/3pillars of counterinsurgency.pdf (8. 7. 2014).

12. Killculen, D. J., 2006a. Twenty-Eight Articles: Fundamentals of company-level Counterinsurgency. http://navsci.berkeley.edu/ma154/C10\%20MAGTF\%20PrePos\%20 Expeditionary\%200ps/InstAid\%20III-6-B\%20-\%20kilcullen_28_articles.pdf (29. 5. 2014).

13. Oestergaard, J. K., 2014. About the Small Dameter Bomb. http://www.bga-aeroweb.com/ Defense/Small-Diameter-Bomb.html (23. 7. 2014).

14. Otten, K., 2009. Dutch Aviation Support/Dutch Aviation MEDIA BV, Slovenian Exprerience. http://www.dutchaviationsupport.eu/Articles/Slovenia-UK.pdf (20. 8. 2014).

15. Petter-Bowyer, P. J. H., 2012. Winds of Destruction - The autobiography of a Rhodesian combat pilot. http://www.rulit.net/books/winds-of-destruction-the-autobiography-of-arhodesian-combat-pilot-read-295068-1.html (21. 7. 2014).

16. Pilatus. The Advanced Trainer: PC-7 MkII. http://www.pilatus-aircraft.com/\#45 (23. 7. 2014a).

17. Pilatus. The Advanced Trainer: PC-9 M. http://www.pilatus-aircraft.com/\#42 (23. 7. 2014). 
18. Pravilo lovačko-bombarderske avijacije, SSNO-KRVi PVO, 1978. Beograd.

19. Radulović, V., 1985. Osnovi vazduhoplovne podrške snaga teritorialne odbrane. Beograd: Vojnoizdavački zavod.

20. Ratković, B., in ostali, 1981. Vojni leksikon. Beograd: Vojnoizdavački zavod.

21. Rendulić, Z., 1974.Vazduhoplovne doktrine-gledišta i tehnika. Beograd: Vojnoizdavački zavod.

22. Trimble, S., 2007. US Air Force Planners Want Irregular Warfare Wing. http://www. flightglobal.com/news/articles/us-air-force-planners-want-irreguar-warfare-wing-215281/ (23. 7. 2014).

23. Van Heerden, R., 2012. Four Ball, One Tracer: Commanding Executive Outcomes in Angola and Sierra Leone. Solihull: Helion \& Company.

24. Venter, A. J., 2008. War dog: Fighting Other People's War, Drexel Hill: Casemate.

25. Waldron, G., 2013. LIMA: Air Tractor goes on the offensive. http://www.flightglobal.com/ news/articles/lima-air-tractor-goes-on-the-offensive-383891/(17. 3. 2014). 